\title{
A arte impura da citação: Jarmusch-Paterson-Derrida
}

\author{
Hugo Monteiro \\ IF/FLUP; INED-ESE/IPP
}

Resumo: A relação entre literatura e cinema, no modo como desafia o pensamento e as fronteiras artísticas, possibilita formas de citação que pertencem ou quase definem um processo criativo. Citar é reposicionar, ler, recitar - repetir transformando, numa experiência fatalmente impura. Partindo de Paterson, de Jim Jarmusch, do ritmo da poesia de William Carlos Williams e baseando a sua leitura na Desconstrução de Jacques Derrida, este artigo retoma a relação entre cinema e literatura a partir do problema da citação como "arte impura".

Palavras-chave: Repetição, Espectro, Cinema, Poesia

\begin{abstract}
The relation between cinema and literature, in the way it defies artistic thought and boundaries, allows for quotations which belong to or very nearly define the creative process itself. To quote is to relocate, to read, to recite - to repeat transforming, in fatally impure experience. Departing from Paterson, by Jim Jarmusch, from William Carlos Williams poetic rhythm, and based on Jacques Derrida's Deconstruction, this paper reclaims the relationship between cinema and literature focusing on the quotation as "impure art".
\end{abstract}

Keywords: Repetition, Specter, Cinema, Poetry 


\section{Abertura}

Em entrevista a Cahiers du Cinéma, ao reconhecer a importância da música na sua concepção de cinema, Jim Jarmusch não deixa de assinalar a aversão pelo vício do que considera um processo de sobreposição intrusiva. A música, essencial nos seus filmes, não deve cair na tentação de se sobrepor à narrativa como uma espécie de "ditado" de sentimentos, não deve sequer "reforçar qualquer coisa". A música deverá surgir no processo final como que "tecida no estofo do filme" (Jarmusch 2016: 20).

Sublinhamos: tecida, em vez de sobreposta. Não estando em causa neste texto a música no cinema ou a música em Jarmusch, o seu posicionamento ilustra uma forma de relação procurada e outra evitada: a tessitura no lugar da sobreposição, que no caso procuramos transpor para a relação entre cinema e literatura. Reposicione-se o cuidado nesta relação possível: buscar o vínculo renunciando à hierarquia; privilegiar a tessitura face à sobreposição ou ditado. Na relação entre literatura e cinema, procuramos antes de mais o ponto em que uma é citável na outra, no corpo uma da outra, como que bordada no seu tecido ou tatuada na sua pele.

Essa hipotética tatuagem motiva esta reflexão. Fugindo do exercício da aproximação pontual ou do "diálogo" em que, contas feitas ao que se entende pôr em comum, cada elemento permanece no seu próprio e afastado lugar, reclama-se um contacto entre literatura e cinema que responda à dinâmica da impressão profunda. A citação é, por hipótese, o nome dessa impressão.

Partindo-se de uma citação, no que entenderemos como um filme-citação - Paterson (2016), de Jim Jarmusch - pelo modo como permanentemente se engendra num jogo de citações e numa dinâmica de repetições que se problematizam no próprio processo fílmico, estará em questão a experiência da citação na relação entre literatura e cinema. A desconstrução de Jacques Derrida, na sua abordagem às "artes do visível" e na sua relativamente breve incursão pelo cinema, modela o tom e atravessa um discurso atravessado pela insistência de uma experiência de citação sempre impura.

Não há citação pura. Nenhuma transposição textual deixa intacto o seu ponto de origem, que é também um ponto cego, um ângulo morto, uma zona em que o exercício de 
interpretação, que toda a leitura comporta, se divide entre a fidelidade ao texto originário e a experiência de infidelidade inerente a todo o acto de ler. A citação é um movimento do texto, uma transposição de espaço ou mesmo de fronteiras em que uma "perda de contexto" suspende a disposição passada e reorganiza a disposição presente (Lopes 2003: 169).

A partir de Paterson, sob o magnetismo da desconstrução, falaremos da citação como arte impura, do deslize na arte da repetição. Como perspectivar uma citação em cinema? Pode uma imagem recitar? Ou re-citar? E com isso, nesse acto de recitar ou de re-citar, constituir-se desde logo como um enunciado movente de todo o acto de citação, de recitação, de récita ou de leitura? Em literatura como em cinema?

Continuamos, citando, repetindo desde o princípio e testando essa repetição ao longo de toda a trama.

\section{Gémeos: Repetição versus Rotina}

No decurso de um texto sobre Georges Bataille, Maurice Blanchot reflecte de passagem sobre a citação, sobre a citação pretensamente fiel, no modo como interpela a posição frágil de quem se coloca perante uma obra. Blanchot, no tempo meteórico de uma passagem brevíssima, alerta para a diferença fundamental entre uma citação e uma mera reprodução: a citação desloca, destaca e sublinha (Blanchot 1969: 301), decorre da experiência transformadora da leitura, que nada deixa intacto. Toda a citação fiel habita o território da infidelidade, passando pelo acto de "deslocar, de exilar o texto do seu suporte, de o arrancar do seu contexto para lhe oferecer um outro local (uma nova página em branco)" (Hoppenot 2014: 18).

Passemos ao filme. No início de Paterson, aparentemente, o exercício deslocalizador da citação. No seu interior, por outro lado, a reprodução de uma rotina de trabalho, a passagem das horas - mas também o instante potencialmente disruptivo em que, numa repetição em problematização permanente, o poema acontece. No interior de uma citação fílmica: a rotina, a repetição, o poema. Vejamos.

Às primeiras horas da manhã, Paterson inicia a sua rotina. 0 relógio marca 6:11, é segunda-feira. Tem ainda tempo para ouvir o balbucio de Laura, sua esposa que, sonolenta, 
diz ter tido um sonho em que ela e Paterson eram pais de dois gémeos. Toma o pequenoalmoço e, no caminho rotineiro para a central de camionagem, Paterson dedica uma aguda e sossegada atenção a tudo, acena a transeuntes, entre os quais dois irmãos já de idade avançada, gémeos e vestidos de igual que lhe devolvem a saudação num gesto sincronizado. Ainda antes de começar a jornada de trabalho, Paterson iniciará a escrita de um poema. Ainda antes do dia terminar Paterson encontrará um título para esse poema, que vai escrevendo nos sucessivos intervalos dos dias seguintes.

Desde o início, em torno de Paterson, a repetição, a série, a duplicação num processo alusivo, passageiro ou literal: os gémeos a surgirem dos sonhos, das ruas, dos enredos e ao longo de todo o filme; Paterson, o condutor de autocarros na cidade de Paterson, o trabalhador-poeta em Paterson e aparente protagonista de um filme com o mesmo título, com o mesmo nome "Paterson".

A questão de uma repetição, que não necessariamente uma referencialidade, colocase desde logo. Paterson repete, começa por repetir, intitula-se repetindo e talvez seja logo aí, antes mesmo de começar o filme, que o problema da repetição se coloque. Ao princípio, ou mesmo antes do princípio, uma repetição. Uma repetição plural e pluralizada. Uma repetição desdobrada em várias outras repetições e uma hesitação fundamental, permanente. Perante nós, Paterson. Paterson, filme de Jim Jarmusch (2016), ou Paterson, poema longo de William Carlos Williams (1958, na sua versão final). Ou, ainda e certamente, como elemento espacial comum ao poeta e ao cineasta, no livro de 1958 e no filme de 2016, Paterson-cidade, a cidade suburbana de Paterson.

Perante nós, Paterson, sem que saibamos ainda que planos assume este filme/ poema/ local perante as instâncias diversas de que é nome comum: não sabemos ainda se Paterson é uma citação fílmica (Williams lido por Jarmusch), se é um ponto referencial comum, mas independente (a cidade perante Williams e Jarmusch), se é o nome de um encadeamento sistemático (a cidade perante Williams, o poema perante Jarmusch). Não sabemos também das possíveis combinatórias entre todas estas possibilidades no modo como afirmamos, de forma quase constativa, que perante nós temos Paterson.

Mas temos também, uma vez imersos no filme, um personagem, de nome "Paterson", 
com o mesmo nome da cidade onde habita e que atravessa quotidianamente, repetidamente, como condutor de autocarro: Paterson motorista, que é também Paterson poeta. Paterson que insiste silenciosamente, obstinadamente, em escrever a poesia de uma cidade que se lhe configura como nome e como morada. Já não perante Paterson, mas antes dele - antes dele personagem, antes dele filme - há a sugestão do que ele repete - o quotidiano da cidade, o longo poema de um poeta nascido em Paterson, de seu nome William Carlos Williams - e que nele se reengendra, filmicamente e poeticamente.

Ao princípio, pois, a repetição. Ou a repetição em vez de um princípio, indício de uma falsa duplicidade ou de uma alternativa artificial que, na verdade, reclama uma interpenetração, um processo e uma experiência de leitura e de visionamento, uma forma de citação. Ou o seu problema.

\section{Da poesia-cinema ao cinema-poesia}

$\mathrm{Na}$ já citada entrevista, Jim Jarmusch reconhece o poema homónimo de William Carlos Williams como um dos pontos de partida para Paterson, ainda que, de forma potencialmente desconcertante, confesse alguma resistência e até desagrado quanto ao que considera um certo hermetismo do poema. 0 que retém de Williams estaria mais evidente noutros textos:

pequenos relances de detalhes vulgares pelos quais se revela algo de belo, uma reacção humana a qualquer coisa modesta, como um carro de mão, um camião de bombeiros ou ameixas em cima de uma mesa. (Jarmusch 2016: 11)

Esta abordagem, aparentemente estranha ao que se consideraria uma vulgar relação de influência entre linguagens artísticas que se tocam, intensifica a interrogação quanto ao que realmente se partilha, quanto aos limites de leitura e quanto ao alcance de uma citação, apesar de tudo admitida. Paterson, de Williams, é realmente um dos pontos de partida para o filme de Jarmusch. Outro ponto de partida, não menos indirecto, está na própria cidade de Paterson, que é realmente "uma versão inventada e fantasmática de Paterson" (ibidem). Mas talvez este olhar de viés da parte de Jarmusch constitua motivo maior para a eficácia da 
sua citação cinemática. Na busca do detalhe revelador de beleza, na deambulação algo flanêur pela cidade imaginada, no jogo permanente de repetições e de duplicidades como formas de construção de intensidades, temos o jogo de cometimento e de lateralidade necessariamente envolvidos na relação literatura-cinema. Vejamos como esta ideia é passível de ser desenvolvida a partir de uma espécie de poética comum a Williams e a Jarmusch, nas suas duas formas de (re)conceber Paterson.

Em nota de abertura a Paterson, William Carlos Williams tinha já associado a formulação de ideias no poema ao reconhecimento e transporte da localização mundana e urbana das coisas, aparentemente isoladas. Na verdade, esta associação quase se enuncia como uma identificação, que sintetizaria a motivação escrevente de Paterson:

[...] porque o homem é em si mesmo uma cidade começando, procurando, alcançando e concluindo a sua vida através de caminhos em que os vários aspectos de uma cidade podem ganhar corpo - quando imaginativamente concebidos - em qualquer outra cidade, podendo todos os seus pormenores exprimir as suas mais íntimas convicções. (Williams 1998: 11)

Reivindicando aquilo que considera um outro modo de ver, Williams reforça: "o homem é na verdade uma cidade" (idem: 12). É preciso escrever rente às coisas. Numa afirmação quase literalmente fenomenológica, Williams parte de uma espécie de intenção recolectora, em si mesma bastante associável à linguagem do cinema, que lhe possa permitir "encontrar uma imagem suficientemente ampla que reunisse todo o mundo reconhecível à minha volta". Prossegue Williams:

Quanto mais tempo permanecesse onde vivia, com todos os acontecimentos da minha vida, mais me apercebia que estas observações e experiências isoladas necessitavam de um trabalho harmónico para assim adquirirem "profundidade" (idem: 13)

A ida ao encontro dessa "imagem ampla", tal como a missão poética do alcance dessa "profundidade" através de uma harmonização de experiências isoladas, levam-nos a um encontro quase óbvio com a experiência do cinema. Não apenas pelas possibilidades técnicas do travelling, da montagem ou do grande plano, que quase imediatamente se 
associam às palavras prévias de Williams, mas pela abordagem ao tempo e à imagem como matérias fundamentais para a prossecução do percurso. Caberia ao poema de Williams, na sua deambulação imagética, revelar, reanimar, reanimar revelando, para assim permitir que, através do poema, essa "profundidade" adormecida nas coisas "se erguesse esvoaçante de vida" (idem: 14-15). O poema é o tempo próprio, ao mesmo tempo reprodutor e inventivo, da imagem que é preciso despertar e a que urge responder:

As quedas de água deixam escapar um rugido conforme se esmagam contra as rochas na sua base. $\mathrm{Na}$ imaginação este ruído é um discurso, uma voz, especialmente uma fala; o próprio poema é a resposta. (idem: 15)

Trata-se de traduzir, dar voz às coisas na linguagem da imaginação, mas ao mesmo tempo trata-se de responder. 0 poema comporta esta missão dupla e não sucessiva, ao mesmo tempo e num mesmo tempo. Assume esta missão num panorama que ilustra singularmente uma "condição cinemática da poesia” (Martelo 2016a: 213), na evidência de, para lá da mera lógica de influência, nos debatermos com um espaço de linguagem partilhável entre as duas artes. Quase adivinhamos uma intersecção possível entre poesia e cinema na imagem que se projecta e que se produz, no próprio som ["este ruído é um discurso..."], no tempo como problema e como experiência (Martelo, 2016b). Sendo que todo este enredo repercute ou reposiciona a questão de uma tradução (poética/ cinemática) obrigada ao desvio, ao reposicionamento e à excedência. Encontramos num dos poemas de Paterson o verso que constitui a melhor formulação para esta lógica de reconhecimento inventivo: “Sem invenção nada fica bem no seu lugar” (Williams 1998: 66).

Nada sem invenção, parece dizer-nos Williams. É essa a condição de uma palavra que se quer rente às coisas. 0 imperativo da invenção afirma-se sobre tudo, inclusive sobre a própria permanência. Não há lei sem invenção. E não há repetição sem novo engendramento.

Estamos perante um poema cujas linhas nos traçam, tanto na tradução quanto no imperativo da invenção, as coordenadas de um espaço cantável, em todas as suas proporções. No ângulo da paisagem, como no pormenor, como no interstício, o lugar é 
matéria de invenção poemática, sendo a limpidez desta invenção a devolução da "profundidade" das coisas, no desígnio quase husserliano de poética de Wiliam Carlos Williams. Uma profundidade de mãos dadas com o que, literalmente, corresponderia a uma devolução de dignidade das coisas, da maior à mais ínfima. Dignidade quase literal, isto é, elevação ao dizível e ao visível, o que implica também e necessariamente a devolução do indizível, como mistério constitutivo de todas as coisas em todas as proporções. A dizibilidade poética das coisas é tanto maior quanto mais nitidamente o indizível se evidencia e o invisível transparece. Está à espreita o processo de vitalização pelo poema, singularmente afirmado por Herberto Helder, em Photomaton \& Vox: ..."o poema vitaliza a vida se a toca nalguns pontos. / O poema gera uma vida nesses pontos tocados" (Helder 1995: 146).

Em suma, a "invenção" que se posiciona no texto de Williams poderia bem constituir-se como palavra provisória para a imagem como experiência/produto onde poesia e cinema se interceptam, partilhando-se sem se confundirem. As imagens são matéria de invenção, de relação e de leitura, sendo aí mesmo partilha intensiva entre poesia e cinema. Por hipótese, o excesso experimentável em poema-imagem corresponde a uma energia de instigação na imagem que permanentemente se cita e se recria.

Mas lembremos a declarada reserva de Jarmusch quanto à complexidade do poema de Williams.

Em Paterson, o poema em imagem perde literalmente a fonte que cita, quando a fidelidade de leitura é imediatamente posta em causa por Jarmusch. A citação, que permanece, silencia o texto como fonte originária, tornando-se imediatamente outra coisa um processo secreto de leitura, uma duplicação tão evidente mas ao mesmo tempo tão intrigante quanto os pares de gémeos que desfilam ao longo de todo o filme. Repetindo-se no seu nome, no seu título, no gesto de um poema urdido nos espaços onde a repetição do quotidiano não chega, todo este jogo de repetições assume uma dimensão deslizante. Repete-se, para se proferir de novo, como poesia-cinema decisivamente reposicionada como cinema-poesia. 


\section{"We have plenty of matches in our house"}

No centro da tela, o poema.

Jim Jarmusch reivindica à poesia, especificamente à que percorre Paterson, uma "espécie de abertura” inacessível à ficção ou à prosa. Tomando Apollinaire como exemplo, Jarmusch sublinha o modo como o próprio espaço visual da página, o jogo de margens que contorna a mancha gráfica do texto, indicia essa abertura, espécie de respiração visual que pertence ao surgimento do poema (Jarmusch 2016: 10).

O poeta de Paterson alimenta a sua escrita nos intervalos de uma rotina repetida, entrecortando o tempo maciço. Colocada no centro, é a poesia que preside a toda a visualidade, fulcro de leveza que invade, afinal, todo o espaço fílmico. A poesia duplica o tempo e sobreleva-o, ela própria gémea de uma vida uniformemente organizada pela rotina de um motorista, Paterson, na cidade de Paterson, Nova Jérsia. Uma cidade ela própria assombrada pela poesia de William Carlos Williams, por Allen Ginsberg, pela trepidação poética de cidadãos ilustres, colecionados na parede em "Shades Bar", que de certa forma reconfiguram o seu estatuto de cidade periférica: a cidade-poema desdobrando a cidadetrabalho, a cidade-rotina. 0 motorista-poeta Paterson deambula entre estes universos, numa deambulação suspensiva que contorna a trama do mundo, que lhe suspende o prosaísmo para revelar a quieta poesia das coisas.

Da rotina de Paterson, na sua repetição quase mecânica no horário do piquete, na serialização disciplinada dos dias de trabalho e dos tempos de descanso, surge um efeito de reconciliada serenidade. Paterson nada reivindica, não sonha - escreve, e é como se todo o filme fosse já um produto de uma poesia de suave coincidência com o lado cantável das coisas, do mundo. Paterson é o poeta de Paterson. Paterson é o condutor do autocarro que, no percurso contínuo pela cidade de Paterson, mediará poeticamente uma experiência de mundo em que o sobressalto não vinga.

O que escreve Paterson? Uma vez mais a coincidência, a serenidade da ida às coisas, a fulguração dos sentimentos que nelas acaba por surgir, poeticamente mediado, entre tempos, entre séries, entre repetições. 0 primeiro poema de Paterson, no evoluir do filme, surge a partir de uma caixa de fósforos. De um produto uniformizado, de fabrico em série, 
do mais raso quotidiano. Surge o poema de um produto indistinto e serializado no seu processo de produção; fósforos ou, reforçando-se em inglês no seu jogo de correspondências, "matches": "we have plenty of matches in our house", escreve Paterson.

O início do poema, no múltiplo indistinto - "plenty of matches" -, confirma uma poética do quotidiano, do objecto uniforme, de um começo pela confirmação da circularidade, também presente nos círculos que Laura, esposa de Paterson, vai pintando e bordando obstinadamente. Poeta do espontâneo, do ready-made, do repouso nas pequenas coisas inertes e apagadas, este Paterson fílmico acena subtilmente ao Paterson-poema, à maneira de William Carlos Williams: "Que há para dizer? a não ser que/ a beleza passa despercebida" (1998: 122).

Reforçando, porém, o processo de duplicidade e de replicação aqui interrogados, "plenty of matches" é ao mesmo tempo a afirmação das muitas correspondências que, teimosamente, desfilam pela narrativa fílmica no seu permanente cortejo de pares de gémeos. A singularidade que excede estes "matches" ou, se quisermos, o deslize para a dissemelhança, o combate silencioso contra o curso monótono das indistinções faz-se poeticamente, nas horas mortas onde o poema se congemina. E faz-se de muitas maneiras. É possível ignorar a subtil irradiação política de Paterson? A reinvenção poética de uma cidade suburbana onde, "longe do realismo social" (Jarmusch 2016: 11), se mantêm as diferenças, as distinções, a miscigenação? 0 labor singularizador de uma escrita tecida nos intervalos do horário de trabalho, como uma sinuosa afirmação do direito à literatura? A poesia nascida dos instantes conquistados à disciplinada sucessão do trabalho e do descanso, "interrupção imperceptível, inofensiva, dir-se-á, do curso normal das coisas, onde se prepara, se sonha, se vive já o impossível” (Rancière 2012: 8)? Ou o remoque da poeta precoce de "Waterfalls", notando o irónico desfasamento do motorista que gosta de Emily Dickinson? Como se no desdobramento da série, no outro lado da repetição, a singularidade da afirmação estivesse pronta a anunciar-se?

O curso do poema tende para esse registo de singularidade, para a vez de uma só vez, pela emancipação do singular sobre a série no tempo da poesia, do amor, da morte discreta: o fósforo, "tão sóbrio e furioso e teimosamente pronto/ a explodir numa chama/ 
Acendendo, talvez o cigarro da mulher que amas/ Pela primeira vez/ E nada foi como dantes depois disso".

É o momento da interrupção, da emancipação face à cópia, da celebração do único instante. Sabemos que a trama de uma repetição ronda o filme do princípio ao fim, de cabo a rabo, de fora para dentro. De Paterson, duplicado e indeciso entre nome, lugar, filme ou poema - até ao ninho de enredos em que a circulação dos dias, dos percursos, de toda uma harmonia circulatória que a poesia - enfim - interrompe sem resolver. Paterson é o gémeo da sua própria rotina. Repete-a poeticamente, na poesia das coisas, que fluem nessa repetição para o momento único em que o poema acontece.

Por isso, Paterson repete Paterson. Como um eco, que importa esclarecer, mas que parte todo ele de um falso constativo, potencialmente ouvido já desde o ímpeto do poeta originário: “Como te amo? Assim!” (Williams 1998: 61). Ouçamos em reverberação de eco.

\section{Eco-grafias: fazer a literatura falar no cinema}

Um eco da literatura no cinema ou, no caso, um filme projectando a seu modo um eco compósito com a poesia no centro - até que ponto isto permite evidenciar uma forma de citação? Ou, até, uma citação que esclarece uma relação entre cinema e literatura, toda ela em forma de citação? Ou de eco?

Chamando especificamente o pensamento de Derrida, a sua leitura particular sobre a narrativa clássica de Eco, sublinhemos a natureza deslizante, transgressora e rebelde que vive na repetição, ao mesmo tempo uma condenação e uma recriação. Até que ponto o universo de Paterson, tal como o filma Jarmusch, pode constituir uma irradiação do acto criativo de fazer cinema lendo? E, nesse caso, justificar-se como um exercício e uma experiência de deportação da palavra (Derrida 2013: 87) sujeita à lei das imagens, que fazem essa palavra falar de outra forma e repetir falando de toda uma outra maneira.

Lendo a narrativa milenar de Ovídio, Derrida fala-nos da punição de Eco (Derrida 1997: 18-20), a quem foi imposto nada dizer por si mesma. Eco foi condenada à repetição e sentenciada a limitar a sua fala ao final de cada frase que lhe fosse dirigida, senão mesmo só à última palavra. Ficaria sujeita, por imposição ditada pela tirania dos ciúmes, a nada dizer 
de original. Eco falaria em segundo, ficando a sua expressão limitada à repetição submissa da fala de Narciso. Nada diria de seu, ou nada diria, ponto.

Ardilosamente, contudo, Eco reinventa o seu dito quando, em insurreição discreta, acaba por falar na repetição e através dela. Repetindo, Eco fala citando, reencaminhando a palavra repetida. A artimanha de Eco, nesta lógica de citação inventiva que é também uma fábula de desobediência estratégica, atravessa toda a experiência da língua, na leitura de Derrida. Porque toda a língua é herdada, anterior, provinda de um passado imemorial que fala antes e que, sempre imprópria (porque de apropriação impossível), nunca se possui. Mas também porque, por outro lado, é preciso que algo aconteça de novo, e para isso é preciso que a língua fale de novo, que se faça ouvir num novo timbre dando a ouvir "uma palavra nova, um novo idioma, um nome próprio: Eco" (Bernardo 2011: 258).

A engenhosidade de Eco está em fazer operar a diferença entre reprodução e repetição dado que, ao repetir, Eco não reproduz nem duplica; Eco desloca as palavras ditas, afirmando as mesmas palavras mas em toda uma outra deriva de sentido. A citação é o expediente rebelde de Eco, numa estratégia permitida pelo ponto cego da sentença imposta. A repetição das palavras de Narciso era apenas aparente na voz de Eco, quando "o fragmento repetido se transformava numa frase completa, inventada, original e expressa, para quem a podia ouvir, em seu nome assinado Eco, sem que nunca a prova do selo a pudesse expor à vingança divina" (Derrida 1997: 19).

A repetição ecoa, ressoa e oscila. Enquanto repetição, e em Derrida, ela é o rastro de uma língua herdada, que se não possui (Derrida 2001a: 39-40), cujo corpus não podemos senão repetir mas que, como língua herdada, é reinventada pelo herdeiro, na pluralidade apaixonada do seu eco. E, tal como Eco, na discreta rebelião da sua experiência da língua, tal herança é reinscrição, contra-assinatura, pluralização da língua nunca una (Derrida 1988: 38). A repetição é, por outro lado, sempre atravessada pela diferença, na "lógica da iteração" (Derrida 2001b: 368) que a trespassa e na vez de cada repetição. Não há repetição que não venha na sua vez, que a não produza enquanto acontecimento, uma e outra vez.

No cinema como na literatura, no filme como no livro, a repetição denuncia uma impossibilidade de plena coincidência. Sublinha a importância do deslize, da fuga e da 
deriva. A repetição é impossível enquanto tal pela diferença que nela se insinua por cada vez e de cada vez, sendo que a sua necessidade, o seu imperativo, mas também a sua impossibilidade rasuram a origem, ou o momento originário, ou o momento zero de qualquer arké. A repetição é impossível enquanto tal porque, já contaminada pela impureza do desvio, pelo espaço em branco da elipse, ela é efeito de diferença - transporta-a, evidencia-a, quase brandindo em enunciado o verso de William Carlos Williams: "Sem invenção nada fica bem no seu lugar". Como bem formula Joana Matos Frias, à margem de uma leitura de Agamben e com o cinema/poesia por foco, “a repetição é nómada" (Frias 2016: 153), não se fixa nem estagna. Só se fala a partir dela.

No início está a repetição, condição de surgimento de qualquer signo (Derrida 1967: 432). Este nasce da divisão e esvazia qualquer centralidade referencial, por ser estruturalmente elíptico. A repetição desloca, recita, contra-assina e desvia... como no filmepoema de Jarmusch/ William Carlos Williams. Ele surge como exemplo privilegiado, não apenas de uma singular força de cruzamento entre cinema e literatura, mas também, no modo singular como dispõe este cruzamento, da forma como o cinema "revoga a primitiva ordem mimética" (Pita 2007: 76) que presidiu à relação entre arte e verdade. A citação inventiva de Jarmusch retoma plenamente cada uma destas dimensões.

\section{Mimografias}

Em explícito contorno da questão "O que é a literatura?", e desviando-se da busca essencialista de uma certa economia do espaço literário, Derrida põe em cena uma pluralização da mimesis (que não imita de uma só vez nem de uma vez por todas), associada ao que entende por "auto-duplicação" ou "proliferação infinita" da repetição (Derrida 1972: 235). 0 que significa a sua emancipação, tanto da submissão a um modelo de verdade, que a colocaria à mercê do argumentário de Platão (1993: 595a - 607b), quanto da subordinação ao modelo real que é imitado na forma da imitação, o que a entregaria à mão fundadora de Aristóteles (2011: 1447a - 1448b). A via proposta traça, pois, uma leitura subversora da tradição estética, filosófica e literária que pontuou o longo caminho da mimesis, por intermédio do Mimo de Mallarmé, em tudo o que dará a pensar de novo. 
É perante "Mímica", de Mallarmé, que Derrida medita sobre o mimodrama capaz de retomar a mimesis sob todo um outro engendramento. Como se sabe, "mimesis" é uma palavra-chave nos discursos disciplinares em torno das Artes, sendo que a sua tradução no termo "imitação", como diz Derrida, produz historicamente os modos de uma relação entre arte e verdade (Derrida 1972: 238). No longo curso da tradição, a mimesis segue as coordenadas de uma verdade existente ou em processo, sendo esta verdade o seu referente soberano. É esta linha de continuidade, de certa forma reconstituída no advento do cinema (Morin 1997), que o mimodrama de Mallarmé interrompe à sua maneira. Uma linha de continuidade que a própria escrita como experiência, prefigurada na reconversão do castigo pela estratégia de Eco, trata de interromper.

Na leitura de Derrida, o Mimo de Mallarmé separa-se em absoluto de qualquer modelo de adequação à verdade, quando nada prescreve os seus gestos ou o desenho mímico da sua escrita (Derrida 1972: 239). Esta "escrita gestual" tem o mesmo traçado hieroglífico da dança ou da pantomima, às quais nenhum ditado discursivo é imposto (idem: 240). Tempo e espaço são reorganizados pelos gestos do Mimo, produzindo a singularidade do evento perante Mallarmé, que o lê. Escrevendo sobre si, em si próprio e nas várias camadas da página em branco que é a sua própria pele, o Mimo apresenta-se como elemento de escrita para o próprio Mallarmé, perante Mallarmé escrevendo-se e dando-se como página em branco para uma outra experiência de escrita.

O Mimo, surgido a Mallarmé através de um libreto de pantomima - Pierrot Assassin de sa Femme - tem a injunção de nada imitar (quase gémeo invertendo Eco), de ser ao mesmo tempo página e pluma (idem: 244), o que põe entre parêntesis o efeito de apresentação do próprio livrinho que o apresenta, aberto à leitura de Mallarmé. A palavra muda do Mimo reclama a estrutura aporética de uma cópia sem modelo, cuja particular subversão do tempo, do espaço e do meio formula a experiência da escrita (incluindo, neste registo, a experiência do cinema, que, como reconhece Derrida (2013: 97) coloca a questão da mimesis de toda uma outra maneira) sob o signo de uma espectralidade que importará deslindar: presença do ausente; desafio à sucessão temporal e arrumação espacial pela quase-presença dos espectros, no texto, na tela - na literatura; no cinema. Importa 
esclarecer, ainda que demasiado brevemente, este regime de espectralidade, no modo como é partilhado pelas duas instâncias em causa.

\section{Espectrografias}

Não deixando de sublinhar o seu vínculo maior à leitura e à escrita, Derrida admira a possibilidade de um mecanismo de projecção, na experiência do cinema, fazer face a todo o género de interditos (Derrida 2013: 317). O cinema permite uma relação particular com a imagem enquanto instância que tudo permite (idem: 317-318). A imagem no cinema é espectral, na exacta medida em que, convocando como nenhuma outra o modo como o inconsciente assombra as modalidades da presença, acciona uma dança de espectros afirmada como centro de toda a experiência do cinema. Como uma "irrealidade" afirmada na realidade (Derrida 1993: 216), como um rasgão no tempo, as imagens do cinema assombram-nos como fantasmas moventes, no registo da "estranheza familiar" (unheimlich) de sentido freudiano, confirmando a proximidade entre psicanálise e cinema cedo reconhecida, por exemplo, por Walter Benjamin (Derrida 2013: 320).

Conversando em torno de Ghost Dance, filme de Ken McMullen (1983) onde desempenha o seu próprio papel, Derrida relembra que o cinema, definido enquanto "arte dos fantasmas", põe em destaque particular o problema da reprodução (Derrida 2013: 308) e dos seus dispositivos. Ao contrário do que veicula uma determinada cultura popular, coadjuvada por toda uma linha de tradição discursiva, a experiência da espectralidade e do fantasma não se orienta para o passado, tornando-se ao contrário mais evidente com a acentuação das tele-tecnologias, dos dispositivos de comunicação ou de gravação (Derrida/Stiegler 1996: 14). A distância torna-se presente, joga às escondidas com a estreita modalização da presença e das fronteiras entre real e irreal. No caso do cinema, o fantasma é colocado no centro, como a imagem que vem e que regressa sem que se possa afirmar como ausente ou presente; a imagem convoca uma presença que não se presentifica, uma ausência que está lá, viva e morta ou nem viva nem morta.

A resposta de Derrida, sua própria personagem em filme, quando confrontado com a questão “-Acredita em fantasmas?", é por isso lucidamente irónica. Quando a pergunta é 
colocada numa situação cinematográfica e desde o interior do cinema, quando é posta a um filósofo que é actor de si mesmo, num filme registado e potencialmente projectável até ao infinito, está-se realmente a perguntar a um fantasma se acredita em fantasmas. Nesta situação, responde Derrida, eu deixo um fantasma falar no meu lugar. E ao reproduzir a sua resposta, neste mesmo instante em que abrimos o dispositivo de reprodução e passamos este fragmento de Ghost Dance, é o fantasma de Derrida que nos fala, que nos define o Cinema (e a Psicanálise) como Ciência de Fantasmas. Assombrando especificamente o interior de uma definição de cinema, esta espectralidade toma palavra e imagem, na recusa de uma simples e tradicional oposição entre estas duas instâncias.

A escrita, envolvendo palavra e imagem, diz respeito a uma experiência de textualização inerente também às artes do visível, mas igualmente um mutismo absoluto em toda e qualquer obra, como resistência ao discurso e à hegemonia discursiva (Derrida 2013: 22). Sem negar as suas diferenças, as artes partilham essa subtracção face ao definitivamente dito ou ao plenamente mostrado. A obra é inesgotável, inconsumável e inconsumível (idem: 39), o que a furta necessariamente à ordem do visível, da presença ou da submissão a um referente. Daí a sua espectralidade, tão claramente inscrita no cinema como experiência: "um espectro é alguém ou alguma coisa que se vê sem ver [...]. 0 espectro é o que se pensa ver, "pensar" desta vez com o sentido de 'crer"” (idem: 59).

O cinema dá a ver, mas nem por isso reduz ao visível nem se entrega a qualquer regime de visibilidade. Ao contrário, no cinema "o pacto com o real não é um pacto com o visível" (Pita 2007: 76), mas com uma invisibilidade que nele se manifesta - a visibilidade do invisível. Daí esta relação com a crença, na dimensão espectral que a requisita:

Há no cinema uma modalidade do crer bem singular: inventou-se há um século uma experiência da crença sem precedentes [...]. No cinema crê-se sem crer, mas este crer sem crer permanece um crer. (Derrida 2013: 321)

Tal como a própria literatura, o cinema para Derrida convoca uma experiência da espectralidade (Derrida 2013: 319) que se concebe de mãos dadas com a questão da repetição. Como tudo o que se furta à plena presença ou à totalidade do tempo e do ser, o 
cinema é a possibilidade técnica e a experiência artística que evidencia, de forma muito particular, a alteridade irredutível como permanente assombração do instante, da sua repetição, da sua fuga. Como escreve, em $O$ monolinguismo do outro, lembrando a proximidade etimológica entre fantasma e phainesthai, o fantasma, o duplo ou o espectro (Derrida 2001a: 40) marcam a incoincidência de um tempo desarticulado, que falsifica a sua linearidade aparente. Trata-se de uma inscrição e, ao mesmo tempo, de um limite da fenomenologia enquanto pensamento de um puro aparecer: o fenómeno é espectral, ou seja, dá sem desvendar o mistério constitutivo que sempre o atravessa, que assombra o seu surgimento.

A fenomenologia, enquanto lógica de um puro aparecer na linearidade do tempo sucessivo, é afectada e perturbada pelo espectro, cujo surgimento traz à experiência a "não contemporaneidade a si do presente vivo" (Derrida 1993: 16). Ele é a experiência de um tempo desajustado, na ausência que regressa, revém, dá-se à experiência fora das categorias tradicionais do tempo, que o tempo do/no cinema tão bem evidencia. Tal lei anacrónica do fantasma reclama também todo um outro pensamento da repetição, quando o processo de revisitação do espectro, sendo uma repetição e sendo repetível, repete-se de cada vez como primeira e última vez. Como reforça Derrida, "um espectro é sempre um regressado [revenant]", pelo que sempre "começa por regressar" (idem: 32). 0 seu presente está atravessado por apóstrofes e a sua experiência é devida, no cinema, ao "efeito hipnotizante das imagens fílmicas" (Bernardo 2017: 71). 0 retorno do espectro conta com a configuração especular do espectador, que acolhe em singularidade a dissonância desse retorno.

A adesão convocada pelo cinema enquanto singular experiência da espectralidade reflecte-se e demonstra-se no Paterson fílmico, na sucessão de duplicidades que, de cada vez e a cada vez, falam por si em cada correspondência: Paterson (poeta) falando de Paterson (cidade), falada desde Paterson (poema), no filme que fala por si mesmo, como uma citação traída, na citação como arte impura. A longa e errante abordagem de Jarmusch - em Paterson mas já, por exemplo, em Dead Man (1996), em que um personagem, William Blake, enreda-se, numa viagem para a morte, com o universo pictórico e poético desse 
outro, universal artista, William Blake - traduz-se na mais indisciplinada das citações, mas também na fina exemplaridade de uma relação entre literatura e cinema.

\section{Da imagem escrita}

Toda a imagem transporta uma duplicidade indecisa. Toda ela mostra, manifesta, revela, mas ao mesmo tempo isola, obscurece o contorno, compõe o espaço de que é imagem como uma forma de o dizer novamente, diferentemente. Toda ela executa uma espécie de efeito de biombo sobre essa duplicidade, que freme por múltiplos sentidos, e dáse enganadoramente como una - a montagem corresponde a esse efeito de ocultação, que escreve e compõe o tempo das imagens.

A questão da escrita, aqui, abrange e associa imagem e palavra. 0 trabalho fílmico sublinha-se como um trabalho de corte, de edição, de montagem (Derrida 2013: 95), cujas possibilidades são profusamente exploradas por todo o lado onde há escrita. De Platão, a Dante, a Blanchot a montagem põe-se em cena em "jogos de ritmos, de enxertias de citações, de inserções, de mudanças de tons, de mudanças de línguas” (Derrida 2013: 328). Como atesta Derrida, há algo como "uma visão cinematográfica do mundo na escrita" (ibidem). Este contágio, permitido e sublinhado no conceito de montagem, reflecte a sombra do irrepresentável, na imagem como na palavra. A montagem, a mesma que Deleuze definiu como imagem indirecta do todo do tempo (Deleuze 1983: 50), intensifica afinal o processo de distanciamento entre a imagem e o que esta supostamente representa. 0 tempo da imagem no cinema não cessa de sublinhar esta distância.

0 tempo da imagem no cinema não corresponde, pois, à ancestral ambição da visão total e linear, alimentada pela clareza objectiva e cartesiana. Uma ambição que chegou a ensaiar o seu ressurgimento na apresentação do cinematógrafo, no momento fundador do dispositivo-cinema. Em texto motivado pela relação entre palavra e visão, já Maurice Blanchot rejeitava a imposição de um modelo óptico capaz de subjugar palavra (e imagem) à dialéctica excludente visível-invisível (Blanchot 1969: 38), com natural preponderância da visão como clareza enunciativa. Nem visível nem invisível, a realidade manifesta-se fora desse dualismo, não abdicando do excesso, da distância, do segredo ou do sonho, de todas 
as dimensões que circulam pelo mundo na margem desse horizonte de estreiteza. A imagem - não apenas no cinema, mas de forma evidente na experiência do cinema - é o índice perfeito desse excesso, dessa indocilidade a um modelo disciplinar de discurso, no legado da mais preponderante definição da Modernidade.

Longe da reprodução ou da imitação, a imagem, como alertava Blanchot, é "a duplicidade da revelação" (idem: 42). Ela desdobra em vez de duplicar, flecte em vez de repetir; a imagem transporta o movimento de obliquidade que não a deixa estagnar e que continuamente reendereça para outras imagens, para memórias de imagens. Como também Jean-Luc Nancy dirá, diante do cinema de Abbas Kiarostami, a imagem, em vez de realidade segunda, é a "mobilidade como essência da presença e presença como vinda, vinda e passagem" (Nancy 2008: 49). A imagem como a palavra, o cinema como a literatura, partilham a fuga ao império da luz e da visibilidade ao partilharem morada no que se mostra e manifesta como invisível e como indizível (Monteiro 2014: 309). No coração dessa partilha, no cinema da poesia que aqui se possibilita e seguindo a injunção de Rosa Maria Martelo, "há que procurar na poesia o fundo da imagem (em movimento) que ela contém" (Martelo 2016a: 29).

\section{Fecho: o mito de Paterson}

Abrimos Che cos'è la poesia?, de Derrida. Confrontamo-nos com a vontade de deixar a citação em suspenso, longe de qualquer comentário:

Não há poema sem acidente, não há poema que não se abra como uma ferida, mas que não abra ferida também. [...] Ele ocorre, então, no essencial, sem que tenhamos de o fazer: ele deixa-se fazer, sem actividade, sem trabalho, no mais sóbrio pathos, estranho a qualquer produção, sobretudo à criação. 0 poema chega-me, bênção, vinda do outro. Ritmo mas dissimetria. (2003: 9)

Atentemos no espaço deixado em branco na citação. Mesmo que suspensa, a marca do parêntesis "[...]" designa um corte propositado no texto original, a marca desfigurante da leitura. Hipoteticamente violenta ou intrusiva, certamente impura como citação, em branco fica o espaço em que Derrida refere a "ferida áfona" do poema, o silêncio que atravessa a 
sua vulnerabilidade: "chamarás poema a uma encantação silenciosa, à ferida áfona que de ti desejo aprender de cor" (ibidem).

Reclama-se o transporte do silêncio na palavra, o resguardo do silêncio, que deixa de ser ausência de palavra ou anulação de discurso para, pelo contrário, deslocar-se para o centro da palavra como dom, na poesia como no cinema. No avesso do posicionamento metafísico que contrapõe imagem a palavra, a experiência da literatura (do cinema) une-as no silêncio que transporta e partilha. A cinemato-grafia resiste à autoridade do discurso neste silêncio.

Permanece em suspenso a citação. Ela atesta também a devolução da palavra "experiência" - que aqui convocámos repetidamente como "experiência cinematográfica" ou "experiência do cinema" - à ideia de provação, de imprevisto, mas também de viagem ou de travessia (Bernardo 2017: 64). Fora da acepção disciplinar, no sentido predominante na Modernidade, a noção de experiência "excede largamente e infinitamente as categorias de subjectividade e de objectividade" (Derrida 2013: 71). Esta ideia de experiência não vem sem vulnerabilidade, na entrega de quem lê, de quem escreve, de quem se dá à visitação imprevista do fantasma na ex-posição do espectador de cinema ou na literatura enquanto experiência. Vindas de algures as imagens chegam-nos, o poema frequenta-nos. A aversão ao léxico autonómico da "produção" ou da "fabricação" é clara quando sabemos que as imagens chegam no ritmo do acontecimento, fora da esfera do sujeito e sem previsão ou programa. 0 cinema acontece como escrita.

Paterson, ainda. Sublinhando desta vez a vulnerabilidade desse fazer-se do poema, da poesia como cinema e do cinema como poesia.

Vemos, enfim, o caderno de Paterson feito em pedaços. É irrecuperável para Paterson. E irrecuperável para nós enquanto espectadores de cinema, por mais que, 
recomeçando o filme, apreciemos novamente o caderno intacto. De cada vez que o filme recomece, e sempre que a experiência do cinema realmente aconteça, os poemas ressurgirão sempre, de novo, e partirão sempre, para sempre.

Espectralmente regressam, fantasmas sempre imprevisíveis e apenas semipresentes. A repetição do filme e o reinício da trama não garantem, desde que haja cinemaliteratura, a possibilidade de um fecho resolutivo da narrativa, como se o círculo se fechasse em definitivo. Paterson regressa à rotina, Paterson escreve fora dela, Paterson lamenta a destruição definitiva dos seus poemas. Paterson repete e repete-se, volta espectralmente em cinema e em poema. Paterson é a citação sem cópia, impura repetição deslizante. E repete-se.

Talvez, como Sísifo para Camus, seja preciso imaginar Paterson feliz. 


\section{Bibliografia}

Aristóteles (2011), Poética, 4⿳亠丷a edição, tradução de Ana Maria Valente, Lisboa, Fundação Calouste Gulbenkian.

Bernardo, Fernanda (2011), “Eco-Grafias. Dar à língua: Contra-assinatura, re-invenção e sobre-vivência", Revista Filosófica de Coimbra, no 39, 247-262.

- - (2017), “Derrida e o cinema”, Revista Filosófica de Coimbra, no 51, 51-90.

Blanchot, Maurice (1969), L'Entretien Infini, Paris, Gallimard.

Deleuze, Gilles (1983), Cinéma 1. L'Image-Mouvement, Paris, Éditions de Minuit.

Derrida, Jacques (1967), L'écriture et la différence, Paris, Seuil.

- - (1972), La Dissémination, Paris, Seuil.

- - (1988), Mémoires - Pour Paul de Man, Paris, Galilée.

- - (1993), Spectres de Marx, Paris, Galilée.

- - (1997), "Pregnâncias", in Colette Deblé, Feminino Plural, tradução de Laura Lourenço e Marc-Ange Graff, Lisboa, Fenda, 11-27.

- - (2001a), O Monolinguismo do Outro ou a Prótese da Origem, tradução de Fernanda Bernardo, Porto, Campo das Letras.

- - (2001b), Papier Machine, Paris, Galilée.

- - (2003), Che cos'è la poesia?, tradução de Osvaldo Manuel Silvestre, Coimbra, Angelus Novus.

- - (2013), Penser à ne pas voir. Écrits sur les arts du visible (1979-2004), Paris, Éditions de la Différence.

Derrida, Jacques / Stiegler, Bernard (1996), Échographies de la Télévision, Paris, Galilée. 
Jarmusch, Jim (2016), "Je suis un dilettante - Entretien avec Nicholas Elliot", Cahiers du Cinéma, no 726, 10-24.

Frias, Joana Matos (2016), "'Tudo o que pensa em mim está filmando': Pertença e repetição na poesia brasileira contemporânea", Relâmpago, no 38, Fundação Luís Miguel Nava, 147165.

Helder, Herberto (1995), Photomaton \& Vox, 3ª edição, Lisboa, Assírio \& Alvim [1979].

Hoppenot, Éric (2014), "Au commencement de l'écriture... de la copie à la citation" in Éric Hoppenot / Dominique Rabaté (Eds), L'Herne - Blanchot, Paris, Éditions de L'Herne, 17-24. Lopes, Silvina Rodrigues (2003), Literatura, Defesa do Atrito, Lisboa, Vendaval.

Martelo, Rosa Maria (2016a), o Cinema da Poesia, Lisboa, Documenta [2012].

- - (2016b), "Artes do tempo", Relâmpago, nº 38, Fundação Luís Miguel Nava, 183-195.

Monteiro, Hugo (2014), Maurice Blanchot. A Literatura nos Limites da Filosofia, Coimbra, Palimage.

Morin, Edgar (1997), O Cinema ou o Homem Imaginário, tradução de António-Pedro Vasconcelos, Lisboa, Relógio d'Água.

Nancy, Jean-Luc (2008), La Evidencia del Filme. El Cine de Abbas Kiarostami, tradução castelhana de Irene Antón e Gadea Cabanillas, Madrid, Errata Naturae.

Pita, António Pedro (2007), O Aprendiz de Mundo e Outros Fantasmas, Coimbra, Pé de Página.

Platão (1993), A República, 7ạ edição, tradução de Maria Helena da Rocha Pereira, Lisboa, Fundação Calouste Gulbenkian.

Rancière, Jacques (2012), A Noite dos Proletários. Arquivos do Sonho Operário, tradução de Luís Leitão, Lisboa, Antígona.

Williams, William Carlos (1998), Paterson, tradução de Maria de Lourdes Guimarães, Lisboa, Relógio d'Água. 


\section{Filmografia}

Jarmusch, Jim (1996), Homem Morto [Dead Man], EUA, 116 minutos.

Jarmusch, Jim (2016), Paterson, EUA, 113 minutos.

McMullen, Ken (1983), Ghost Dance, UK, 100 minutos.

Hugo Monteiro é Doutor em Filosofia, professor na Escola Superior de Educação do Politécnico do Porto e investigador no Instituto de Filosofia/ FLUP. Os seus interesses de investigação gravitam essencialmente em torno da relação entre Filosofia e Literatura, com incursões nos domínios da Política ou Educação tendo a Filosofia e o Pensamento Crítico Contemporâneo como referências de base. Co-traduziu o livro de Jean-Luc Nancy, O Peso de um Pensamento, a Aproximação (2011) e tem publicado vários títulos de natureza ensaística, com destaque para Maurice Blanchot. A Literatura nos Limites da Filosofia (2014) ou, mais recentemente, "Cantos do exílio. O algures como elemento do texto em Llansol" (2016), "De uma frágil radicalidade. A passo de gato no pensamento (político) de Jean-Luc Nancy" (2017), "Arrebatamento na distância: Nós" (2018) ou "Exórdio, margem e adenda. Post-Scriptum ao Fim do Mundo" (2018). 